\title{
Following the Clinical and Functional Status of an Adolescent with Cystic Fibrosis: Case Report
}

\section{Cássio Daniel Araújo da Silva*, Nelbe Nesi Santana, Ana Lúcia Nunes Diniz, Roberta Fernandes Correa and Bruna de Souza Sixel}

National Institute of Women, Child and Adolescent Health Fernandes Figueira- IFF/Fiocruz Rio de Janeiro, Brazil

Received: January 20, 2018; Published: January 31, 2018

*Corresponding author: Cássio Daniel Araújo da Silva, National Institute of Women, Child and Adolescent Health Fernandes Figueira- IFF/Fiocruz Rio de Janeiro, Brazil, Email: cd.danielsilva@gmail.com

Abstract

Cystic Fibrosis (CF) is a multisystem genetic disease whose main cause of morbidity and mortality is progressive impairment of lung function associated with loss of quality of life and functional capacity. We report the clinical case of an 18-year-old adolescent accompanied at a reference center with bronchial hyper-secretion, recurrent infections, bacterial colonization, important obstructive ventilatory disorder, and pulmonary computed tomography (CT) showing a heterogeneous pattern. The authors emphasize the importance of continuous monitoring of pulmonary, nutritional and functional parameters, allowing for more effective early interventions.

Keywords: Cystic Fibrosis; Lung Diseases; Evaluation; Follow-up

Abbreviations: CF: Cystic Fibrosis; CFTR: Cystic Fibrosis Trans-membrane Conductance Regulator; PA: Pseudomonas Aeruginosa; FEV1: Forced Expiratory Volume at Firs second; FVC: Forced Vital Capacity; ADL: Activities of Daily Living; 6MWT: Six-Minute Walk Test

\section{Introduction}

Cystic fibrosis (CF) is an autosomal recessive genetic disease of chronic character and systemic involvement, especially of the digestive, reproductive and respiratory systems, where respiratory system disease is the cause of morbidity and mortality [1-3]. Caused by mutations in the gene that encodes the cystic fibrosis trans-membrane conductance regulator (CFTR) protein, it has an estimated incidence of 1: 3,000 live births globally [4,5]. Its natural course involves progressive impairment of lung function through early obstruction and neutrophilic inflammation, making mucociliary clearance difficult and favoring bronchiectasis and respiratory infections, with significant loss of quality of life and functional capacity4-6. Considering the life expectancy of the disease in Brazil, this study aims to report the case of an 18 year - old fibrocystic adolescent and his clinical status and functional capacity in the period between 2010 to 2017, accompanied at a reference center in Rio de Janeiro.

Table 1: Description of pneumofunctional evaluations from 2010 to 2017

\begin{tabular}{|c|c|c|c|c|c|c|c|}
\hline & Feb-10 & Nov-12 & Aug-15 & Sep-16 & Jul-16 & Dec-16 & Mar-17 \\
\hline BMI/age & 12,6 & 14,6 & 2,6 & 0 & 0 & 0 & - \\
\hline$\%$ MIP & 99,1 & 122,0 & - & 134,5 & - & - \\
\hline$\%$ MEP & 71,1 & 125,7 & - & 104,0 & - & 7,3 \\
\hline$\%$ PF & 68,4 & 68,3 & 71,6 & 78,4 & 78,5 & 7,9 \\
\hline \multicolumn{7}{|c|}{ 6MWT } \\
\hline \% predicted & 103,6 & 100,8 & 89,4 & 83,7 & 80,7 & 80,0 & 73,4 \\
\hline MHR & 150 & 124 & 171 & 133 & 172 & 149 & 152 \\
\hline O2 sats & $97 \%$ & $90 \%$ & $97 \%$ & $90 \%$ & $91 \%$ & $92 \%$ & $90 \%$ \\
\hline Borg & 2 & 0 & 2 & 2 & 2 & 2 & 1 \\
\hline
\end{tabular}

BMI: Body mass index; PF: Peak flow; MIP: Maximum inspiratory pressure; MEP: Maximum expiratory pressure; 6MWT: Six-minute walk test; MHR: maximum Heart Rate; O2 sats. 


\section{Case Report}

WDM, 18 years old, male, black, from Rio de Janeiro, diagnosed with $\mathrm{CF}$ at 3 months of age after hospitalization for dyspnea at a municipal hospital. After recurrent hospitalizations, was referred at the age of 1 year for follow-up at a referral center for CF in Rio de Janeiro, where it has been assisted since then. He is currently undergoing severe ventilatory obstruction, chronic colonization by pseudomonas aeruginosa (PA), frequent exacerbations, postural deformities in the chest and spine, chronic malnutrition, inflammatory bowel disease, diabetes mellitus and pattern of pulmonary disease heterogeneous on radiological examination, suffering a total of 8 hospitalizations between January and September 2017, usually due to hypoxemic and respiratory discomfort. The patient has had gastrostomy for less than a year and does not use ventilatory or oxygen support outside the hospital setting. The adolescent has been inserted since September in a pulmonary transplant program in the state of São Paulo, where he waits for a compatible donor. The data presented from the functional evaluation correspond to the period between 2010 and 2017 (Table 1) (Figures 1 \& 2).

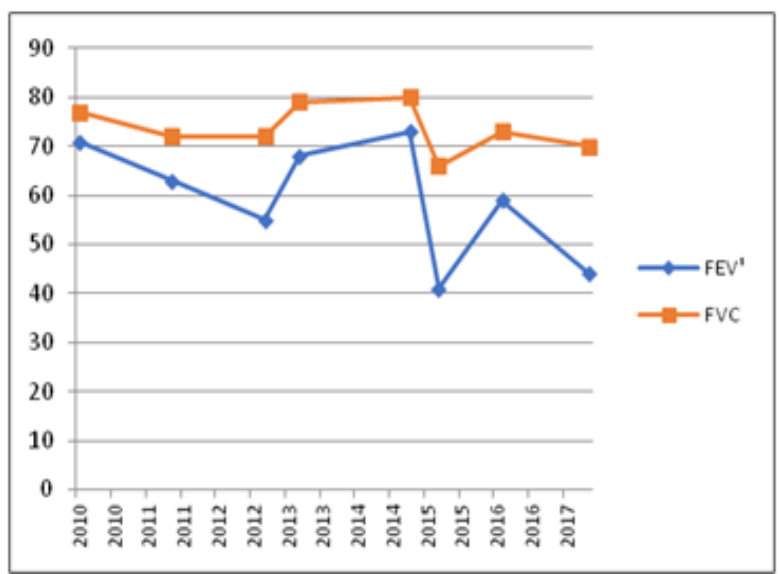

Figure 1: Evolution of the FEV1 and FVC parameters of the pulmonary function test between the years 2010 and 2017.

FEV1: Forced expiratory volume at first second; FVC: Forced vital capacity

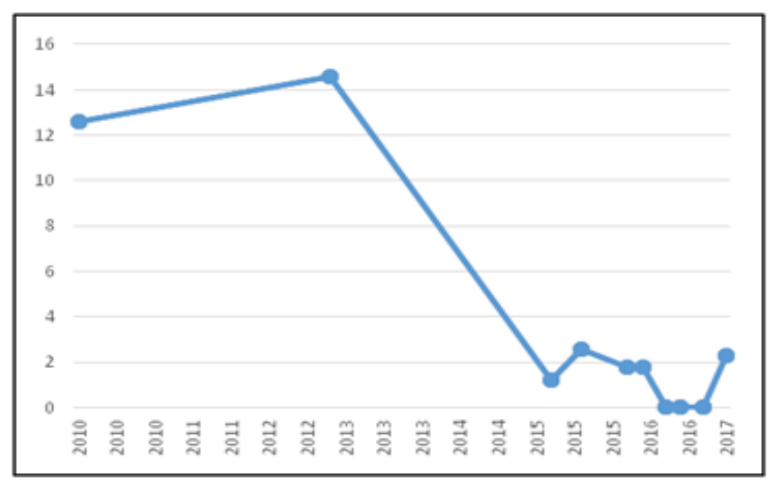

Figure 2: Evolution of the BMI /age percentile between the years 2010 and 2017.

BMI: Body mass index

\section{Discussion}

The multi-systemic consequences of CF are widely known and disseminated, especially on the respiratory system and on the negative repercussions on functional capacity and quality of life [46], reinforcing the importance of the integral and multidisciplinary approach to the patient [7]. In general, the typical clinical aspect of pulmonary disease in $\mathrm{CF}$ involves a cascade of progressive loss of lung function by early obstructive tubulopathy, resulting in deficits in mucociliary clearance and facilitation of bacterial infections and colonization in the respiratory tract, favoring inflammatory reactions which may accentuate lung damage [4-7]. In the reported patient, there was a fall in forced expiratory volume at firs second (FEV1) from $71 \%$ in 2010 to 59\% in 2017, while in forced vital capacity (FVC) there was a loss of less than $10 \%$ in the same period. This ventilatory obstruction, associated with the reduction of the elasticity of pulmonary recoil, limits the ventilatory capacity in these patients, which impacts the functional capacity, impairing the activities of daily living (ADLs) and reducing the survival [8].

Therefore, the functional capacity for the six-minute walk test (6MWT) was also impaired, with a $30 \%$ decrease in the walking distance in relation to the distance predicted in the studied period, which may also be related to the bacterial colonization by PA, since it has been associated with the shorter distance walked in the $6 \mathrm{MWT}$ and the acceleration of the decline of the pulmonary function [9]. Although the assessment of inspiratory and expiratory muscle strength (MIP and MEP) remained within the range of normal, we observed the chronic malnutrition status in which the patient evolved, whose decline increased after 2013. These findings corroborate previous studies by Mark et al. [10] and O'Neills et al. [11], where it was verified that both MIP and MEP were related to the effect of muscle training and not to nutritional status. In this context, we highlight the importance of nutritional status and severity of the disease in the functional capacity and daily activities of CF patients and, consequently, in quality of life, where the approach of respiratory physiotherapy in conjunction with multidisciplinary care should aim at to continuously educate patients and their families, provide support for home treatment, monitor and predict complications, as well as prevention of pulmonary disorders, co morbidities and constant promotion of quality of life [12].

\section{Conclusion}

Considering the chronic and progressive nature of the disease, the authors emphasize the importance of previous recognition of lung morbidity and functional capacity, whose early intervention may be a predictor of therapeutic success.

\section{References}

1. Lumsden MA, Kelly RW, Baird DT (1983) Primary dysmenorrhoea: the importance of both prostaglandins E2 and F2a. Br J Obstet Gynaecol 90(12): 1135-1140.

2. McCracken P (2003) The curse of Eve, the wound of the hero: Blood, gender, and medieval literature. University of Pennsylvania Press. Philadelphia, PA, USA. 
3. Kristjansdottir J, Johansson ED, Ruusuvaara L (2002) The cost of the menstrual cycle in young Swedish women. Eur J Contracept Reprod Health Care 5(2): 152-156

4. Coco AS (1999) Primary dysmenorrhea. Am Fam Physician 60(2): 489496.

5. Deligeoroglou, E (2000) Dysmenorrhea. Ann NY Acad Sci 900: 237-244.

6. Dawood MY (2006) Primary dysmenorrhea: advances in pathogenesis and management. Obstet Gynecol 108(2): 428-441.

7. Marjoribanks J, Proctor M, Farquhar C, Derks RS (2010) Nonsteroidal anti-inflammatory drugs for dysmenorrhea. Cochrane Database Syst Rev 20(1): CD001751.

8. Lundstrom V, Green K (1978) Endogenous levels of prostaglandin F2a and its main metabolites in plasma and endometrium in normal and dysmenorrheic women. Am J Obstet Gynecol 130: 640-646.

9. Chan WY, Hill JC (1978) Determination of menstrual prostaglandin levels in non-dysmenorrheic and dysmenorrheic subjects. Prostaglandins 15(2): 365-375.

10. Chan WY, Dawood MY, Fuchs F (1979) Relief of dysmenorrhea with the prostaglandin synthetase inhibitor ibuprofen: effect on prostaglandin levels in menstrual fluid. Am J Obstet Gynecol 135(1): 102-108.

11. Chan WY, Dawood MY (1980) Prostaglandin levels in menstrual fluid of non-dysmenorrheic and of dysmenorrheic subjects with and without oral contraceptives or ibuprofen therapy. Adv Prostaglandin Thromboxane Res 8: 1443-1447.

12. Chan WY, Dawood MY, Fuchs F (1981) Prostaglandins in primary dysmenorrhea. Comparison of prophylactic and nonprophylactic treatment with ibuprofen and use of oral contraceptives. Am J Med $70(3): 535-541$.

13. Chan WY, Fuchs F, Powell AM (1983) Effects of naproxen sodium on menstrual prostaglandins and primary dysmenorrhea. Obstet Gynecol 61(3): 285-291.

14. Powell AM, Chan WY, Alvin P, Litt IF (1985) Menstrual-PGF2 alpha, PGE2 and TXA2 in normal and dysmenorrheic women and their temporal relationship to dysmenorrhea. Prostaglandins 29(2): 273-290.

15. Proctor ML, Roberts H, Farquhar CM (2001) Combined oral contraceptive pill (OCP) as treatment for primary dysmenorrhoea (Cochrane Review) Cochrane Database Syst Rev 4: CD002120.

16. Ekstrom P, Akerlund M, Forsling M, Kindahl H, Laudanski T, et al. (1992) Stimulation of vasopressin release in women with primary dysmenorrhea and after oral contraceptive treatment: effect on uterine contractility. Br J Obstet Gynaecol 99(8): 680-684.

17. Proctor M, Farquhar C (2006) Diagnosis and management of dysmenorrhoea. BMJ 332(7550): 1134-1138.

18. Marsden JS (2004) Guaifenesin as a treatment for primary dysmenorrhea. J Am Board Fam Pract 17(4): 240-246.

19. Houser GA (1983) Leistungsfahigkeit der zervikalkanaldilatation in der behandlung der dysmenorrhoe. Ther Ums/ RevneTherap 40: 642-645.

20. Kurman (1994) Blaustein's pathology of the female genital tract. Springer New York, New York, USA, pp. 185-201.

21. Gray H, Williams PL (1995) Gray's Anatomy (38 th edn.). Churchill Livingstone, London, England, pp. 1870-1873.

22. O’Brien WF (1995) The role of prostaglandins in labor and delivery. Clin Perinatol 22(4): 973-984.

23. Dawood Y Glob (2008) Dysmenorrhea libr women's med. Glowm, USA.

24. Akerlund M (1979) Pathophysiology of dysmenorrhea. Acta Obstet Gynecol Scand Suppl 87:27-32.

25. Dawood MY (1900) Dysmenorrhea. J Reprod Med 33(1): 168-178.

26. Quraishi MS, Jones NS, Mason J (1998) The rheology of nasal mucus: a review. Clin Otolaryngol 23: 403-413.

27. Marsden JS, Strickland CD, Clements TL (2004) Guaifenesin as a treatment for primary dysmenorrhea. J Am Board Fam Pract 17(4): 240 246 .

28. Letzel H, Megard Y, Lamarca R, Raber A, Fortea, J (2006) The efficacy and safety of aceclofenac versus placebo and naproxen in women with primary dysmenorrhoea. Eur J Obstet Gynecol Reprod Biol 129(2): 162168.

29. Marchini M, Tozzi L, Bakshi R, Pistai R, Fedele L (1995) Comparative efficacy of diclofenac dispersible $50 \mathrm{mg}$ with ibuprofen $400 \mathrm{mg}$ in patients with primary dysmenorrhoea. A randomized, double-blind, within-patient, placebo-controlled study. Intern J Clinical Pharm and Ther 33(9): 491-497.

30. Milson I, Andersch B (1984) Effect of ibuprofen, naproxen sodium and paracetamol on intrauterine pressure and menstrual pain in dysmenorrhea. British J Obstet and Gynecol 91(11): 1129-1135.

31. Lumsden MA, Baird DT (1985) Intra-uterine pressure in dysmenorrhea. Acta Obstet Gynecol Scand 64(2): 183-186.
This work is licensed under Creative Commons Attribution 4.0 License

Submission Link: http://biomedres.us/submit-manuscript.php

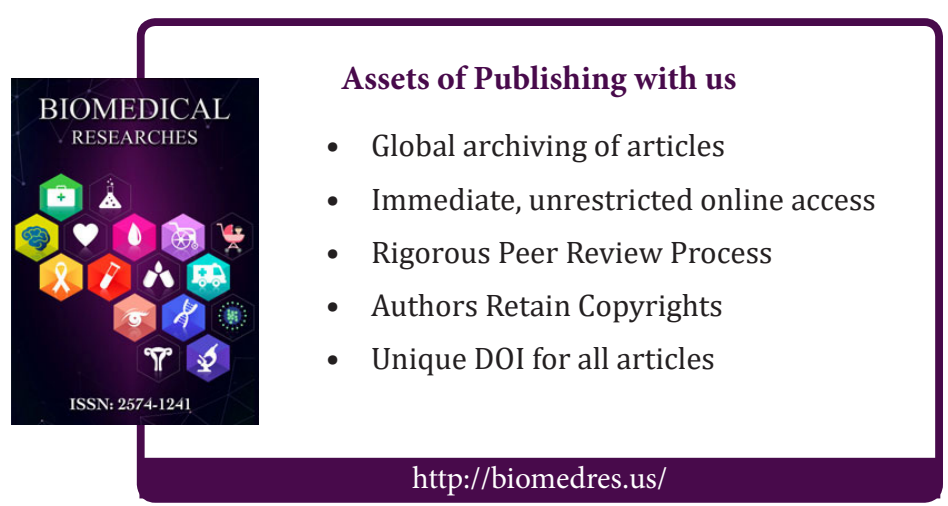

